\title{
Accumulation of eosinophils and T-lymphocytes in the lungs after exposure to pinewood dust
}

\author{
S. Gripenbäck*, L. Lundgren\#, A. Eklund*, C. Lidén`, L. Skare`, G. Tornling*^ and \\ J. Grunewald*
}

ABSTRACT: Exposure to wood dust within the woodworking industry has been shown to cause a variety of respiratory disorders. The aim of this study was to investigate the cellular effects in bronchoalveolar lavage (BAL) fluid and peripheral blood from healthy individuals exposed to pinewood dust.

Eleven healthy volunteers were exposed to pinewood dust for $1 \mathrm{~h}$ in a whole-body exposure chamber. BAL fluid and blood cells were differentially counted and the expression of activation, adhesion and subset markers on alveolar macrophages and T-lymphocytes was determined 26 weeks before and $20 \mathrm{~h}$ after the exposure.

Following pinewood dust exposure, the total BAL fluid cell concentration increased from 81.4 (64.1-97.5) $\times 10^{6}$ cells $\mathrm{L}^{-1}$ (median (interquartile range)) to $195.3(154.6-341.2) \times 10^{6} \mathrm{cells} \cdot \mathrm{L}^{-1}$. The BAL fluid T-lymphocyte concentration increased from $3.8 \%(3.5-6.5 \%)$ to $7.6 \%(4.9-11.2 \%)$, and BAL fluid eosinophil concentration from $0.0 \%(0.0-0.2 \%)$ to $1.8 \%(0.6-3.5 \%)$.

Inhalation of pinewood dust leads to the recruitment of inflammatory cells to the airways of healthy individuals. The increase in numbers of eosinophils, T-lymphocytes and mast cells, i.e. cells of crucial importance to airway inflammation, in the lungs may be related to the increased risk of developing respiratory disorders among woodworkers.

KEYWORDS: Airway inflammation, bronchoalveolar lavage, exposure chamber, pinewood dust

$\mathbf{T}$ he industrial use of wood is an important part of the Swedish economy, employing $1.5 \%$ of the working population (in 2001), including workers in sawmills, joinery workshops, and paper- and furniture-manufacturing industries (Statistics Sweden, Stockholm, Sweden). Health problems associated with the environment of woodworkers are therefore an important issue. Continuous exposure to wood dusthas been shown to be associated with various clinical symptoms. It notonly causes respiratory disease in the upper and lower airways [1-3] but has also been shown to contribute to the development of contact dermatitis due to contact allergy to colophony $[4,5]$ and nasal cancer $[6,7]$.

Wood dust is formed during various operations in wood-processing industries. Exposure levels differ between individual workplaces and also between different tasks within the same workplace. A survey of exposure levels in the Swedish woodworking industry showed that the highest levels are found during operations such as sawing, inspection and polishing, with total dust levels of $0.2-4.1,0.4-5.6$ and $0.3-7.3 \mathrm{mg} \cdot \mathrm{m}^{-3}$, respectively [8]. Workers exposed to wood dust levels within these ranges have been shown to suffer from various respiratory symptoms. Whether other agents in the wood working environment, such as terpenes, could be responsible for the symptoms experienced has also been the subject of discussion $[1,9,10]$.

The purpose of this study was to investigate whether or not there are a cellular inflammatory response in the airways and changes to the blood cells of healthy individuals following pinewood dust exposure. An inflammatory reaction would support a relationship between exposure and respiratory symptoms and subsequent disease. The 11 study subjects were exposed to a total pinewood dust concentration of $5.5 \mathrm{mg} \cdot \mathrm{m}^{-3}$ (median) for $1 \mathrm{~h}$, using a whole-body exposure chamber [11]. Bronchoscopy with bronchoalveolar lavage (BAL) was performed 2-6 weeks before and 1 day after exposure. BAL fluid cells were analysed by differential counting, and phenotypic analyses of alveolar macrophages (AMs) and

\section{AFFILIATIONS}

*Dept of Medicine, Division of Respiratory Medicine, Karolinska Institute.

\# Institute of Applied Environmental Research, Air Pollution Laboratory, Stockholm University.

"Dept of Medicine, Occupational and Environmental Dermatology, Karolinska Institute and Stockholm County Council, Stockholm, and ${ }^{+}$Clinical Science, AstraZeneca Lund, Sweden.

CORRESPONDENCE

J. Grunewald

Dept of Medicine

Lung Research Laboratory L4:01

Karolinska University Hospital

S-171 76 Stockholm

Sweden

Fax: 46851775451

E-mail: johan.grunewald@

medks.ki.se

Received:

May 192004

Accepted after revision:

August 052004

SUPPORT STATEMENT

This study was supported by the National Institute for Working Life, the Swedish Council for Work Life

Research, the Swedish Foundation for Health Care Sciences and Allergy Research, the King Oscar II Jubilee Foundation, the Swedish Heart-Lung Foundation and the Karolinska Institute (all Stockholm, Sweden).

European Respiratory Journal Print ISSN 0903-1936 Online ISSN 1399-3003 
T-lymphocytes from BAL fluid and peripheral blood were performed using flow cytometry.

\section{MATERIAL AND METHODS Subjects}

Eleven healthy volunteers (eight females) with a median age of 25 (range 22-51) yrs participated in the study. Nine were never smokers and two had stopped smoking $>10$ yrs ago (subject Nos. 3 and 9). All subjects underwent a physical examination, including chest radiography and routine blood routine, 2 weeks before the study. None had experienced respiratory tract infection during the month prior to the investigation or had a history of respiratory tract disease. None of the subjects had a history of atopy and all subjects had negative results from radioallergosorbent tests specific for pine and spruce. Serum immunoglobulin E levels were $<120 \mathrm{U} \cdot \mathrm{L}^{-1}$ for all but one individual (subject No. 7: $300 \mathrm{U} \cdot \mathrm{L}^{-1}$ ). The participants gave their informed consent and the local ethics committee of the Karolinska Hospital (Stockholm, Sweden) approved the study.

\section{Exposure to pinewood dust}

The pinewood dust used during the exposures was taken from an exhaust box connected to a sanding machine at a manufacturer of wooden floorboards (Rappgo, Braås, Sweden). The dust was sieved $(100 \mu \mathrm{m})$ and stored in argon before exposure. The study subjects were exposed to the pinewood dust for $1 \mathrm{~h}$ in a whole-body exposure chamber built and constructed especially to give even and continuous generation of airborne dust [11]. Based on the Swedish threshold limit value for wood dust ( $2 \mathrm{mg} \cdot \mathrm{m}^{-3}$ total dust during an 8-h workday), an airborne dust concentration of $\sim 5 \mathrm{mg} \cdot \mathrm{m}^{-3}$ (total dust) was chosen as a suitable exposure level. Prior to the exposures, the wood dust was analysed with respect to living microbes. The presence of terpenes in the airborne dust was analysed during exposure. All exposures were performed at air exchange rates that resulted in replacement of the air in the chamber 12 times per hour.

During the exposure, dust samples were collected at two positions close to the breathing zone on either side of the subject. Total dust was sampled in 37-mm open-faced cassettes (Millipore holder; Millipore, Bedford, MA, USA) and inhalable dust (defined by the European Standardisation Committee (CEN) (1993)), was sampled with Institute of Occupational Medicine samplers (SKC, Blandford Forum, UK). For both samplers, the flow rate was $2 \mathrm{~L} \cdot \mathrm{min}^{-1}$. Respirable dust, defined as airborne particles with a diameter of $<5 \mu \mathrm{m}$, i.e. the dust particle size that the sampler collects with $50 \%$ efficiency [12] was sampled using cyclones (Casella SIMPEDS; Casella London, London, UK) at a flow rate $1.9 \mathrm{~L} \cdot \mathrm{min}^{-1}$. All dust samples were collected on membrane filters made of mixed esters of cellulose with a pore-size of $0.8 \mu \mathrm{m}$ for total and inhalable dust and $8.0 \mu \mathrm{m}$ for respirable dust (Millipore, Billerica, MA, USA), and weighed on a microbalance in a controlled-environment weighing room (55\% relative humidity at $21^{\circ} \mathrm{C}$ ) before and after sampling. The forced expiratory volume in one second (FEV1) was recorded before exposure, immediately after and just prior to the second bronchoscopic procedure on the day after the exposure. FEV1 was expressed as a percentage of the predicted value according to the recommendations of the European Respiratory Society [13].

\section{Bronchoalveolar lavage procedure and cell handling}

Bronchoscopy with BAL was performed 2-6 weeks before and on the day after the exposure. The bronchoscopy procedure was performed as described in detail elsewhere [14]. Briefly, after pre-medication with morphine and hyoscine, bronchoscopy was carried out under local anaesthesia using a flexible fibreoptic bronchoscope (Olympus BF Type P20/30/40; Olympus Optical Co., Tokyo, Japan). The bronchoscope was wedged in a subsegmental bronchus in the middle lobe and a total volume of $250 \mathrm{~mL}$ sterile phosphate-buffered saline (PBS; $\mathrm{pH} 7.4$ ) at $37^{\circ} \mathrm{C}$ was instilled in five aliquots of $50 \mathrm{~mL}$ each. After instillation, the fluid was gently aspirated and collected in a siliconised plastic bottle kept on ice. The BAL fluid was filtered through a single layer of Dacron nets (Type AP32; Millipore, Cork, Ireland) and centrifuged for $10 \mathrm{~min}$ at 400xg at $4^{\circ} \mathrm{C}$. The cells were resuspended in PBS and counted in a Bürker chamber, and cell viability was determined by trypan blue exclusion. Smears for differential counts were prepared by cytocentrifugation (Cytospin 2; Shandon, Runcorn, UK) for $3 \mathrm{~min}$ at $22 \times g$. After staining with May-Grünwald Giemsa, 500 cells were counted, and, after staining with toluidine/ haematoxylin, the number of mast cells in 10 visual fields (16x magnification) was determined.

Venous blood samples were drawn at the time of bronchoscopy and differential cell counts were determined by automated counting using an Advia 120 Hematology System (Bayer Diagnostics, Tarrytown, NY, USA). Peripheral blood monocytic cells were separated from heparinised whole blood by Ficoll Hypaque (Amersham Pharmacia Biotech, Uppsala, Sweden) gradient centrifugation, washed twice and diluted in PBS.

\section{Immunofluorescence and flow cytometry}

Immunolabelling of AMs was carried out using primary unconjugated monoclonal mouse antibodies specific for CD11a (adhesion marker; Dako, Glostrup, Denmark), CD14 (lipopolysaccharide receptor; Dako), CD16 (Fc $\gamma$ RIII; Dako), CD86 (co-stimulatory marker; Serotec, Oxford, UK) and human leukocyte antigen (HLA) class II (activation marker; Dako). Isotype-matched mouse immunoglobulin controls (Dako) were used to determine nonspecific background fluorescence. For each analysis, $5 \times 10^{5}$ BAL fluid cells were incubated with a saturating amount of primary antibody for $30 \mathrm{~min}$ at $4^{\circ} \mathrm{C}$ in the dark. After two washes with PBS, the cells were stained with a secondary R-phycoerythrin (RPE)conjugated $\mathrm{F}\left(\mathrm{ab}^{\prime}\right)_{2}$ rabbit antimouse immunoglobulin $\mathrm{G}$ (Dako) for $30 \mathrm{~min}$. The cells were washed twice, resuspended in Cellfix (Becton Dickinson, Mountain View, CA, USA) and kept on ice until flow cytometric analysis the following day.

For analysis of T-cell subpopulations and expression of T-cell activation markers, $2 \times 10^{5}$ lymphocytes from BAL fluid or peripheral blood were stained with a saturating amount of directly labelled mouse monoclonal antibodies. RPEconjugated anti-CD8 and RPE-/cyanine Cy5-conjugated antiCD4 antibodies (Dako) were simultaneously added together with fluorescein-isothiocyanate-conjugated anti-CD3 (Dako), anti-CD69 (very early activation; Becton Dickinson, San José, CA, USA) or anti-HLA-DR (late activation; Dako) antibodies. After incubation for $30 \mathrm{~min}$ at $4{ }^{\circ} \mathrm{C}$ in the dark, the cells were 
washed twice in PBS, resuspended in Cellfix and kept on ice overnight before flow cytometric analysis.

The samples were analysed in a FACSCalibur flow cytometer (Becton Dickinson, Mountain View, CA, USA), and the cell populations were identified and gated by means of their light scattering properties. Within the macrophage gate, 10,000 cells were collected, and the expression of each surface marker was determined as the mean fluorescence intensity after subtraction of background fluorescence intensity. For the lymphocytes, the percentage of positively labelled cells in the CD4+ and CD8+ subsets were calculated, respectively. Staining with isotype-matched negative control antibodies was $<1 \%$ of the analysed cells in all experiments.

\section{Bronchoalveolar lavage fluid analysis}

BAL fluid eosinophil cationic protein (ECP) was measured using a commercially available fluoro-immunoassay, Pharmacia ECP CAP System FEIA (Pharmacia Diagnostics, Uppsala, Sweden). ECP levels of $<1 \mu \mathrm{g} \cdot \mathrm{L}^{-1}$ were considered a negative result.

\section{Statistical analysis}

The data are presented as medians with interquartile ranges unless otherwise stated. The Wilcoxon matched-pair test was used for comparisons between values obtained before and after exposure in the same individual.

\section{RESULTS}

\section{Wood dust data and levels of exposure}

Microscopic analysis of the wood dust prior to exposure showed that $\sim 95 \%$ was from pinewood, with only trace levels from domestic floriferous trees. Determination of aerodynamic particle size in the air showed two particle modes, at $\sim 8$ and $\sim 25 \mu \mathrm{m}$ (fig. 1). The terpene concentration in the pinewood dust was below the detection limit of the method used $\left(<0.02 \mathrm{mg} \cdot \mathrm{m}^{-3}\right)$ and a long way below the threshold limit value $\left(150 \mathrm{mg} \cdot \mathrm{m}^{-3}\right)$. No bacterial growth was detected.

The dust concentrations in the chamber during the exposures, measured as total dust, inhalable dust and respirable dust,

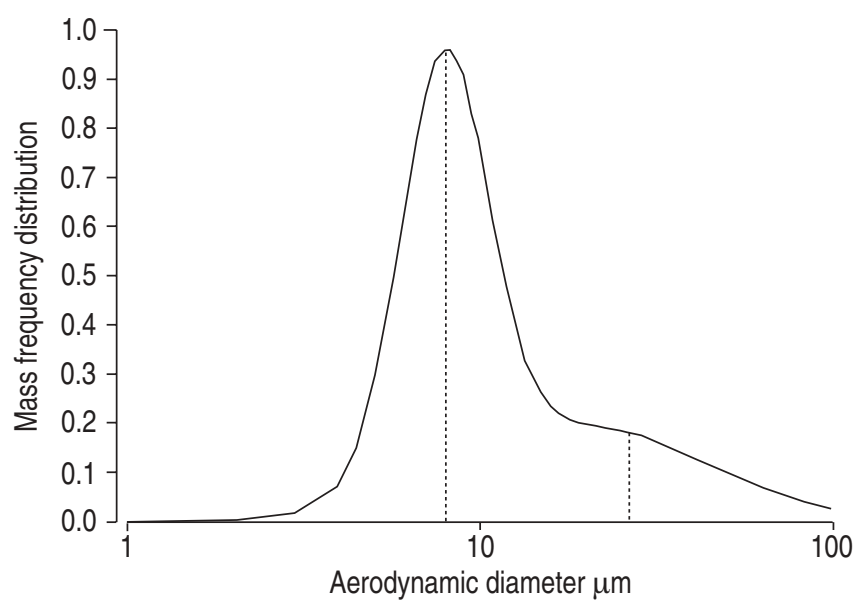

FIGURE 1. Aerosol size distribution of pinewood dust measured in the exposure chamber using cascade impactors at $2 \mathrm{~L} \cdot \mathrm{min}^{-1}$ [15]. Dotted vertical lines indicate peaks of the two particle modes, at $\sim 8$ and $\sim 25 \mu \mathrm{m}$. were $5.5(5.4-6.0), 6.8(6.7-7.4)$ and $1.0(0.9-1.1) \mathrm{mg} \cdot \mathrm{m}^{-3}$, respectively.

\section{Pulmonary function and bronchoalveolar lavage fluid cell count data}

The spirometry measurements did not differ before and immediately after the exposure. However, the FEV1 tended to decrease from 97 (93-111) \% pred before to 95 (92-107) \% pred the day after exposure to pinewood dust $(\mathrm{p}=0.055)$.

BAL fluid recovery and cell viability were $>70$ and $>90 \%$, respectively, and did not differ before and after exposure. Exposure to pinewood dust significantly increased the total number of cells in BAL fluid (table 1). The percentage of lymphocytes and eosinophils in BAL fluid increased significantly (fig. 2), whereas the percentage of AMs decreased correspondingly. Moreover, exposure to pinewood dust resulted in an increased number of mast cells in BAL fluid (table 1). In peripheral blood, there was a significant decrease in lymphocyte and eosinophil numbers (fig. 2), and an increase in neutrophil numbers, whereas monocyte and basophil numbers remained unchanged (table 1). The total white blood cell percentage in peripheral blood remained the same after exposure to pinewood dust.

ECP levels in BAL fluid were analysed in six of the study subjects and were not detectable before dust exposure $\left(<2 \mu \mathrm{g} \cdot \mathrm{L}^{-1}\right)$. After exposure, two individuals (subject Nos. 3 and 11) showed elevated levels ( 2.3 and $3.6 \mu \mathrm{g} \cdot \mathrm{L}^{-1}$, respectively).

\section{Alveolar macrophage phenotype}

Exposure to pinewood dust resulted in an altered AM phenotype in BAL fluid. Following exposure, the AM population was found to be smaller and less granulated, as shown by a significant decrease in mean fluorescence intensity for both side $(\mathrm{p}<0.001)$ and forward $(\mathrm{p}<0.001)$ scatter (fig. 3$)$. Expression of the lipopolysaccharide receptor, CD14, increased significantly after exposure $(\mathrm{p}<0.001)$ (fig. 4$)$. Moreover, the co-stimulatory markers CD11a and CD86 and the activation marker HLA-DR showed a decreased level of expression $(\mathrm{p}<0.001, \mathrm{p}=0.019$ and $\mathrm{p}<0.001$, respectively) after pinewood dust exposure, whereas AM expression of CD16 did not change significantly (fig. 4).

\section{Lymphocyte phenotype}

The percentage of BAL fluid CD4+ T-cells expressing the early activation marker CD69 significantly decreased from $73.4 \%$ $(57.8-79.6 \%)$ before to $60.8 \%(44.6-68.9 \%)$ after $(\mathrm{p}=0.0078)$ exposure, whereas the rest of the BAL fluid T-cell phenotypic data (CD4, CD8 and HLA-DR) did not show any significant changes. Analysis of peripheral blood lymphocytes did not show any significant changes in the expression of CD69 or HLA-DR on either CD4+ or CD8+ T-cells following pinewood dust exposure. Furthermore, the CD4/CD8 ratio remained unchanged in both BAL fluid and peripheral blood.

\section{DISCUSSION}

In the present study, healthy individuals were exposed to pinewood dust for $1 \mathrm{~h}$ in an exposure chamber. Before and after exposure, differential cell counts, as well as phenotypic analysis, were performed on both BAL fluid and blood cells. The present data suggest that exposure to pinewood dust 
TABLE 1 Cell counts in bronchoalveolar lavage (BAL) fluid and peripheral blood from 11 healthy individuals before and after a 1-h exposure to wood dust

\begin{tabular}{|c|c|c|c|}
\hline & Before ${ }^{\#}$ & After & p-value \\
\hline Total cell count $10^{6}$ cells & $16.1(11.0-18.3)$ & $31.5(29.2-66.1)$ & $<0.001$ \\
\hline Total cell density $10^{6}$ cells $\cdot \mathrm{L}^{-1}$ & $81.4(64.1-97.5)$ & $195.3(154.6-341.2)$ & $<0.001$ \\
\hline \multicolumn{4}{|l|}{ BAL cells } \\
\hline Macrophages \% & $95.4(93.0-97.0)$ & $90.0(86.6-93.0)$ & 0.003 \\
\hline Lymphocytes \% & $3.8(3.5-6.5)$ & $7.6(4.9-11.2)$ & 0.019 \\
\hline Basophils \% & $0.0(0.0-0.1)$ & $0.0(0.0-0.2)$ & \\
\hline Mast cells ${ }^{+} n$ & $2.0(0.5-5.0)$ & $6.0(2.5-13.0)$ & 0.004 \\
\hline Total white blood cells \% & $5.3(5.3-6.4)$ & $5.6(5.0-6.2)$ & NS \\
\hline \multicolumn{4}{|l|}{ Total blood cells } \\
\hline Monocytes \% & $7.0(5.5-9.5)$ & $7.0(5.5-8.0)$ & NS \\
\hline Lymphocytes \% & $42.0(36.5-48.0)$ & $34.0(29.0-43.5)$ & 0.020 \\
\hline
\end{tabular}

Data are presented as median (interquartile range). ${ }^{\#}:$ 2-6 weeks before exposure; ${ }^{\bullet}: 1$ day after exposure; ${ }^{+}:$in 10 visual fields (16x magnification). Ns: nonsignificant.

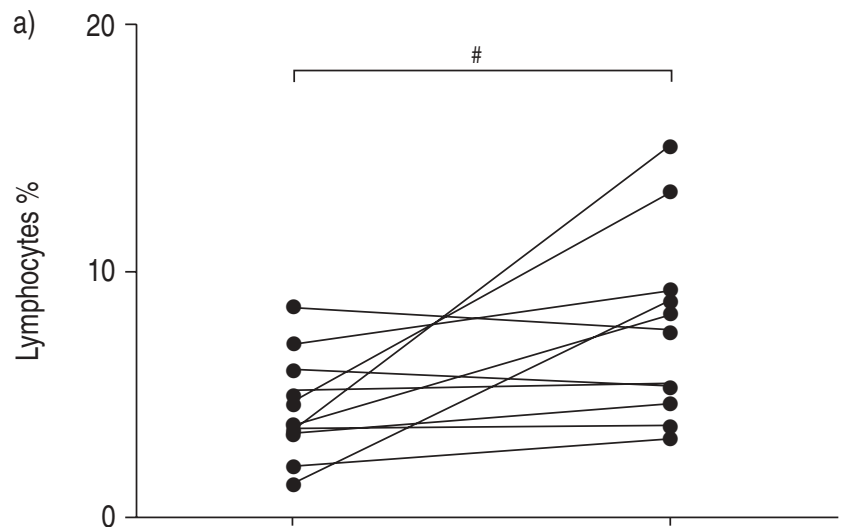

b)
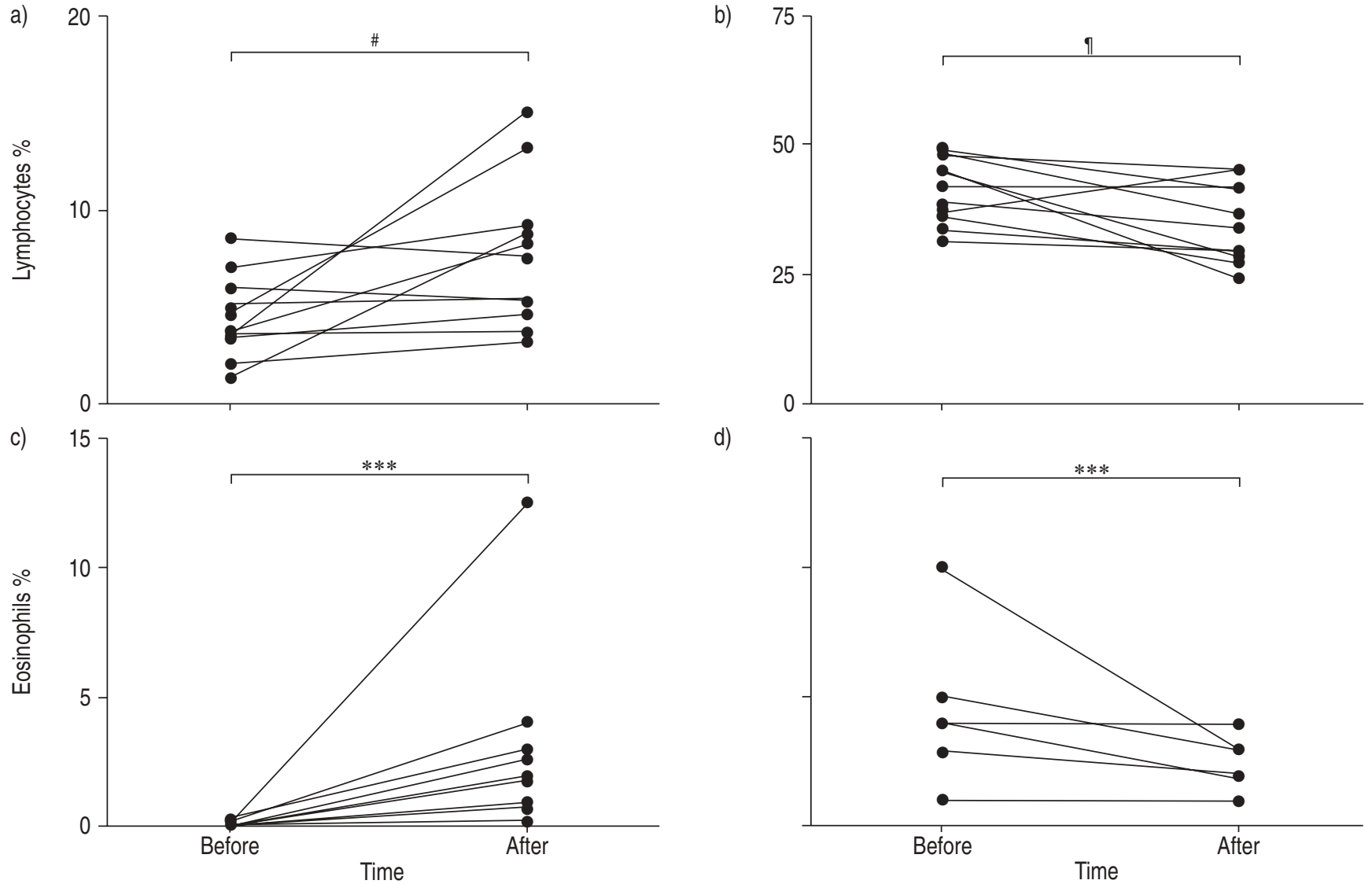

d)

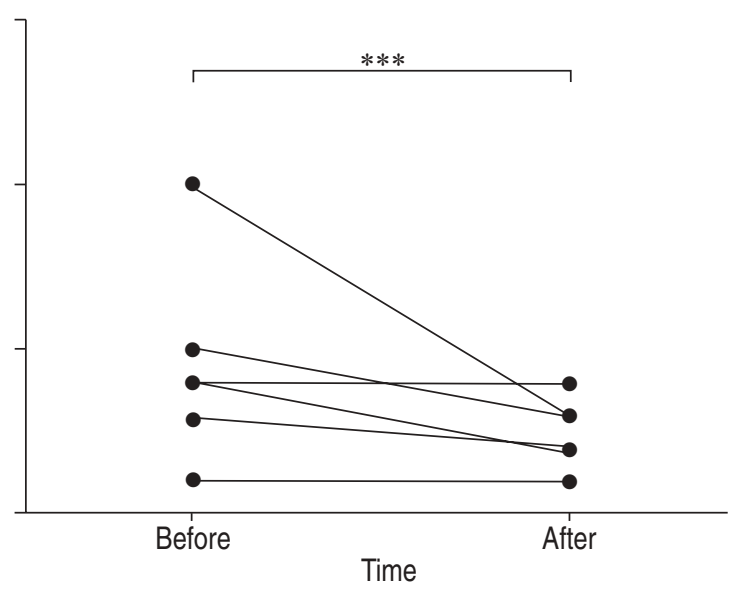

FIGURE 2. Percentage of: a, b) lymphocytes and c, d) eosinophils, in a, c) bronchoalveolar lavage (BAL) fluid and b, d) peripheral blood. BAL and blood samples were taken from 11 healthy volunteers $2-6$ weeks before and 1 day after a 1 -h exposure to wood dust. The different lines represent individual patients. $\#: p=0.188 ;{ }^{*}: p=0.186 ;{ }^{* * *}$ : $p<0.001$. 

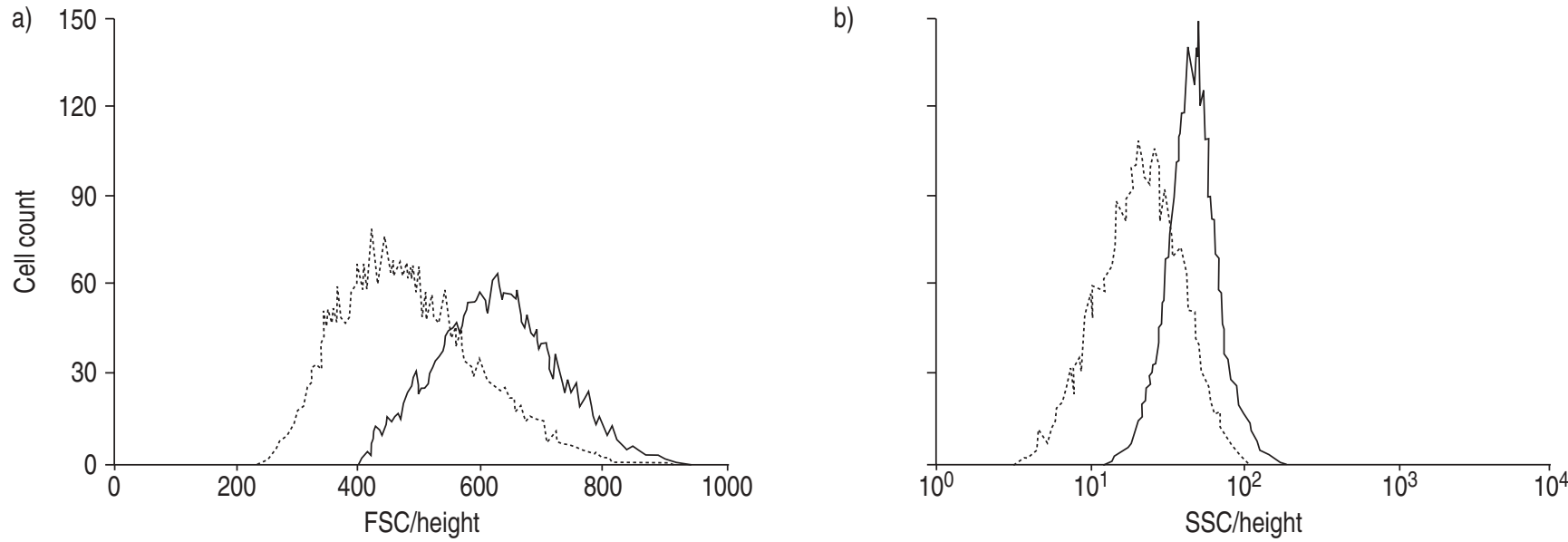

FIGURE 3. Flow cytometric histographic analyses of bronchoalveolar lavage fluid cells from one representative individual (No. 9) showing: a) forward scatter (FSC) and b) side scatter (SSC) 2-3 weeks before $(-)$ and 1 day after $(\cdots \cdots \cdots)$ a 1-h exposure to wood dust.

results in recruitment of eosinophils and lymphocytes from the blood to the lungs. After exposure, a significant increase in BAL fluid mast cell number, as well as an increase in the total number of BAL fluid cells, was also noted. The phenotypic analysis of AMs showed an altered AM phenotype, consistent with an increased proportion of less activated and less differentiated monocytes.

Wood dust exposure may be an underestimated occupational health problem, since $>60,000$ people in Sweden alone are employed in industries using wood. Continuous exposure to wood dust is known to increase the risk of airway disease [1$3]$, contact dermatitis $[4,5]$ and nasal cancer $[6,7]$. In a recent study by Douwes et al. [16], pine sawmill workers were shown more often to have respiratory symptoms, including asthma and cough symptoms, as well as eye and nose irritation. Dust, including wood dust, exposure may also increase the risk of developing chronic obstructive pulmonary disease [17]. Other professional categories exposed to wood include woodworking teachers, who have been shown to exhibit a higher rate of occurrence of symptoms of the skin, nose, throat and lower airways than healthy controls [2]. In the present study, healthy individuals were exposed to wood dust levels similar to those previously reported from real life during wood dust work [8].

One common health problem for woodworkers is asthma [16]. Interestingly, in the present study, it was found that eosinophils, mast cells and lymphocytes (i.e. cells of vital importance to the development of an asthmatic inflammatory reaction), in particular, accumulate in the lungs following pinewood dust exposure [18]. For eosinophils and lymphocytes, a concomitant reduction in cell number was seen in peripheral blood, further indicating the marked shift of these cells from blood to BAL fluid. Eosinophils are considered to migrate into the lungs in response to chemotactic mediators such as eotaxin, in particular, as well as monocyte chemotactic peptide- 3 and -4 , and RANTES (regulated on activation, normal T-cell expressed and secreted) [19]. Although eotaxin is mainly produced by epithelial cells in response to T-helper cell (Th) type 2 cytokines such as interleukin (IL)-5 and -13, the cheomattractants monocyte chemotactic peptide -3 and -4 and
RANTES are produced mostly by monocytes/macrophages upon activation. AMs were also found in higher total number following pinewood dust exposure, although they expressed lower intensities of activation markers, suggesting a reduced activation status. However, the changed AM phenotype and cellular composition indicated an influx of more monocyte-like cells into the BAL fluid, and monocytes may have a high capacity to produce chemoattractant mediators. The increase in BAL fluid eosinophil numbers was, in two out of six cases, accompanied by elevated levels of ECP, suggesting increased activation of the locally accumulated eosinophils following dust exposure. Thus it can be speculated whether a long-term effect of pinewood dust exposure, in some individuals, involves accumulation of activated eosinophils, which could contribute to the higher prevalence of asthma in wood industry workers. The role of T-lymphocytes in asthma entails activated T-lymphocytes with elevated production of the Th2 cytokines IL-4, -5 and -13 , in particular. In the present study, significantly increased numbers of BAL fluid T-lymphocytes, accompanied by a significant decrease in peripheral blood T-lymphocyte numbers, were found following pinewood dust exposure. In addition, there were significantly reduced numbers of CD69positive BAL fluid CD4+ T-lymphocytes after exposure, a phenomenon most probably caused by an influx into the lungs of large numbers of CD69-negative CD4+ peripheral blood T-lymphocytes. Thus there were clear signs of an influx of CD4+ T-lymphocytes into the lungs following pinewood dust exposure, indicating a potentially specific immune reaction locally. However, any distinct role for these cells remains unclear, especially as no cytokines were analysed here.

Previous studies on particulate exposure using the whole-body chamber revealed signs of airway inflammation, with significantly increased numbers of AMs, in particular, following wheat flour exposure [20]. Moreover, healthy individuals exposed to starch showed dramatic signs of lung-accumulated eosinophils after exposure, eosinophils sometimes making up as much as $30 \%$ of all BAL fluid cells [21]. The increase in eosinophil numbers correlated with elevated levels of ECP, indicating eosinophil activation on site after exposure [21]. The hypothesised starch-induced eosinophilic lung accumulation 

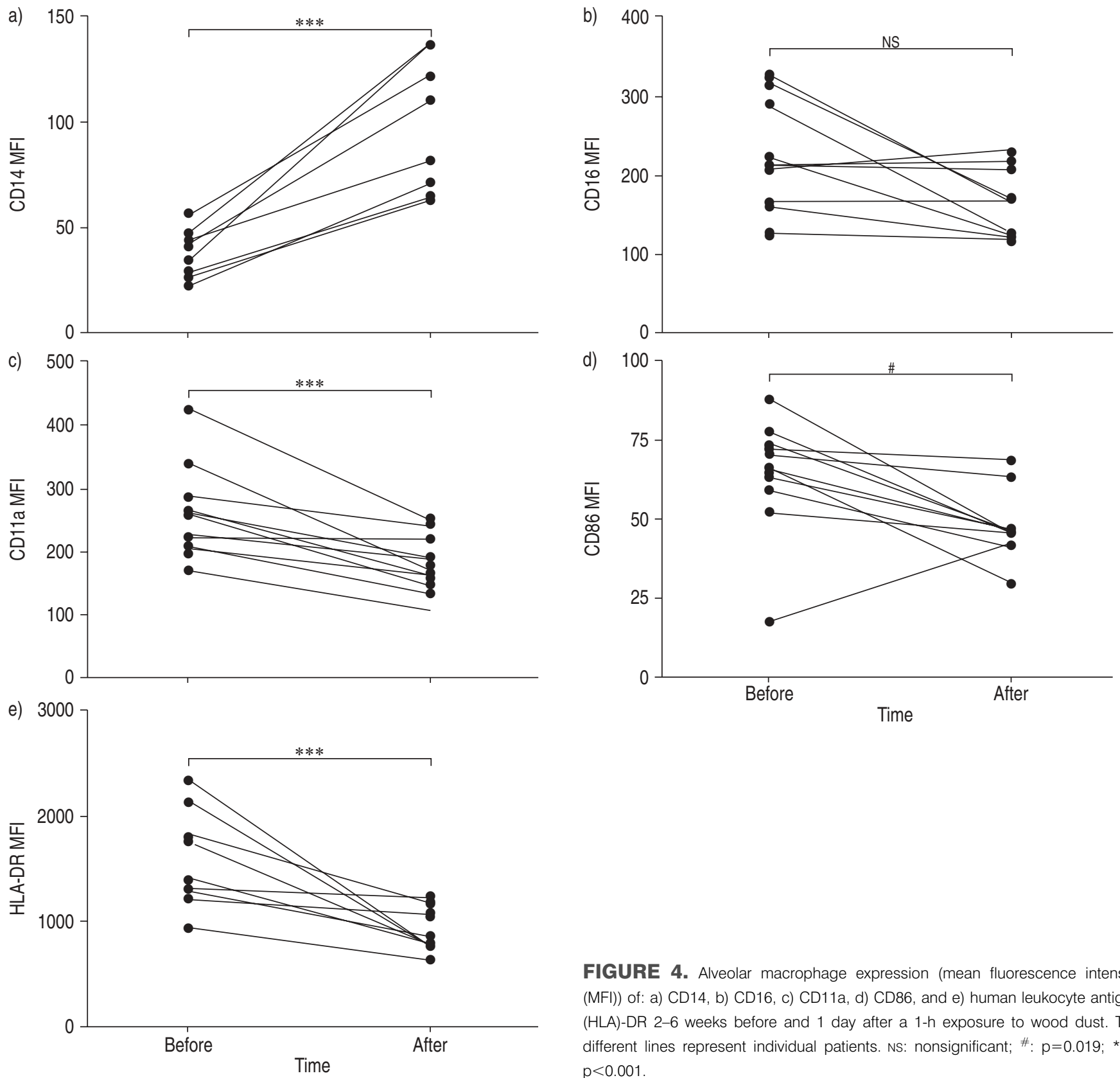

seemed not to be dependent on eotaxin, as eotaxin levels were unchanged after exposure. The importance of a wood dust polysaccharide component in the dramatic lung accumulation of eosinophils following wood dust exposure remains open to speculation. Interestingly, the cellulose component of pinewood dust, but not the fibre extract of the wood dust, has previously been implicated in the induction of pathological changes in the lung, including granulomatous inflammation and fibrosis [22]. Also $(1 \rightarrow 3)$ - $\beta$-D-glucan, a polyglucose cell wall component of fungi, certain bacteria and plants, has been shown to cause an airway response characterised by an increase in eosinophil and lymphocyte numbers in the lung lavage fluid and interstitium of guinea-pigs [23]. Wood dust has also been reported to include endotoxins. However, exposure to endotoxins results in recruitment of neutrophils

FIGURE 4. Alveolar macrophage expression (mean fluorescence intensity (MFI)) of: a) CD14, b) CD16, c) CD11a, d) CD86, and e) human leukocyte antigen (HLA)-DR 2-6 weeks before and 1 day after a 1-h exposure to wood dust. The different lines represent individual patients. NS: nonsignificant; $\#: p=0.019$; $* *$ : $p<0.001$.

[24], which was not registered in the present study. Wood dust may also include terpenes, which have been shown to increase hyperresponsiveness in woodworkers $[9,10]$. In the present study, it was not possible to identify any terpenes in the dust, and there were no dramatic changes in pulmonary function after exposure.

Exposure to swine dust results in acute airway inflammation, including accumulation of large numbers of neutrophilic granulocytes in healthy individuals [25, 26]. Interestingly, chronic exposure among swine farmers leads to a reduced inflammatory response, indicating development of tolerance. A similar situation may be found among individuals chronically exposed to wood dust, as the cellular airway inflammatory reaction described in the present study is not found 
among woodworkers, who instead show a normal BAL fluid cellular composition, but with other signs of low intensity alveolar inflammation [27].

In conclusion, in the present study, significant accumulation of eosinophilic granulocytes and T-lymphocytes, in particular, but also of mast cells, in the lungs after exposure to pinewood dust is described. The present results may be important to the understanding of airway inflammation, common among workers in the wood industry.

\section{ACKNOWLEDGEMENTS}

The authors would like to thank B. Dahlberg, M. Dahl and G. de Forest for skilful technical assistance.

\section{REFERENCES}

1 Hessel PA, Herbert FA, Melenka LS, Yoshida K, Michaelchuk D, Nakaza M. Lung health in sawmill workers exposed to pine and spruce. Chest 1995; 108: 642-646.

2 Ahman M, Soderman E, Cynkier I, Kolmodin-Hedman B. Work-related respiratory problems in industrial arts teachers. Int Arch Occup Environ Health 1995; 67: 111-118.

3 Ahman M, van Hage-Hamsten M, Johansson SG. IgEmediated allergy to wood dusts probably does not explain the high prevalence of respiratory symptoms among Swedish woodwork teachers. Allergy 1995; 50: 559-562.

4 Estlander T, Jolanki R, Alanko K, Kanerva L. Occupational allergic contact dermatitis caused by wood dusts. Contact Dermatitis 2001; 44: 213-217.

5 Meding B, Ahman M, Karlberg AT. Skin symptoms and contact allergy in woodwork teachers. Contact Dermatitis 1996; 34: 185-190.

6 Andersen HC, Andersen I, Solgaard J. Nasal cancers, symptoms and upper airway function in woodworkers. $\mathrm{Br}$ J Ind Med 1977; 34: 201-207.

7 Malker HS, McLaughlin JK, Blott WJ, et al. Nasal cancer and occupation in Sweden, 1961-1979. Am J Ind Med 1986; 9: 477-485.

8 Lidblom A, Arbetarskyddsstyrelsen (National Board of Occupational Safety and Health). Exposition för Damm i Svensk Träbearbetande Industri 1994/1995. Solna, Arbetarskyddsstyrelsen, 1997.

9 Eriksson KA, Stjernberg NL, Levin JO, Hammarstrom U, Ledin MC. Terpene exposure and respiratory effects among sawmill workers. Scand J Work Environ Health 1996; 22: 182-190.

10 Eriksson KA, Levin JO, Sandstrom T, LindstromEspeling K, Linden G, Stjernberg NL. Terpene exposure and respiratory effects among workers in Swedish joinery shops. Scand J Work Environ Health 1997; 23: 114-120.

11 Liden C, Lundgren L, Skare L, Liden G, Tornling G, Krantz S. A new whole-body exposure chamber for human skin and lung challenge experiments - the generation of wheat flour aerosols. Ann Occup Hyg 1998; 42: 541-547.
12 Second Pneumoconiosis Conference, Johannesburg 1959. Recommendations adopted by the pneumoconiosis conference. In: Orenstein AJ, ed. Proceedings of the Pneumoconiosis Conference held at the University of Witwatersrand, Johannesburg, 9-24 February, 1959. London, J\&A Churchill, 1960; pp. 617-621.

13 Quanjer PH, Tammeling GJ, Cotes JE, Pedersen OF, Peslin R, Yernault JC. Lung volumes and forced ventilatory flows. Eur Respir J 1993; 6: Suppl. 16, 5-40.

14 Eklund A, Blaschke E. Relationship between changed alveolar-capillary permeability and angiotensin converting enzyme activity in serum in sarcoidosis. Thorax 1986; 41: 629-634.

15 Gibson H, Vincent J, Mark D. A personal inspirable aerosol spectrometer for applications in occupational hygiene research. Ann Occup Hyg 1987; 31: 463-479.

16 Douwes J, McLean D, Slater T, et al. Asthma and other respiratory symptoms in New Zealand pine processing sawmill workers. Am J Ind Med 2001; 39: 608-615.

17 Trupin L, Earnest G, San Pedro M, et al. The occupational burden of chronic obstructive pulmonary disease. Eur Respir J 2003; 22: 462-469.

18 O'Byrne PM, Postma DS. The many faces of airway inflammation. Asthma and chronic obstructive pulmonary disease. Am J Respir Crit Care Med 1999; 159: S41-S66.

19 Mackay I, Rosen F. Allergy and allergic diseases. $N$ Engl J Med 2001; 344: 30-37.

20 Gripenback S, Lundgren L, Eklund A, et al. Wheat flour exposure results in recruitment of inflammatory cells in the lungs of healthy individuals. Am J Ind Med 2003; 44: 75-82.

21 Grunewald J, Eklund A, Katchar K, et al. Lung accumulations of eosinophil granulocytes after exposure to cornstarch glove powder. Eur Respir J 2003; 21: 646-651.

22 Tatrai E, Adamis Z, Bohm U, Meretey K, Ungvary G. Role of cellulose in wood dust-induced fibrosing alveobronchiolitis rat. J Appl Toxicol 1995; 15: 45-48.

23 Fogelmark B, Thorn J, Rylander R. Inhalation of (1->3)- $\beta$ D-glucan causes airway eosinophilia. Mediators Inflamm 2001; 10: 13-19.

24 Sandstrom T, Bjermer L, Rylander R. Lipopolysaccharide (LPS) inhalation in healthy subjects increases neutrophils, lymphocytes and fibronectin levels in bronchoalveolar lavage fluid. Eur Respir J 1992; 5: 992-996.

25 Larsson K, Malmberg P, Eklund A. Acute exposure to swine dust causes airway inflammation and bronchial hyperresponsiveness. Am J Ind Med 1994; 25: 57-58.

26 Larsson KA, Eklund AG, Hansson LO, Isaksson BM, Malmberg PO. Swine dust causes intense airways inflammation in healthy subjects. Am J Respir Crit Care Med 1994; 150: 973-977.

27 Johard U, Eklund A, Dahlqvist M, et al. Signs of alveolar inflammation in non-smoking Swedish wood trimmers. $\mathrm{Br}$ J Ind Med 1992; 49: 428-434. 